\title{
XE ROHENOI EJU ORENDIVE: RIMAS, RAPPERS E HIBRIDIZAÇÃO CULTURAL DE POVOS INDÍGENAS NO BRASIL
}

\section{Xe Rohenoi Eju Orendive: Rhymes, Rappers and Cultural Hybridization of Indigenous Peoples in Brazil}

William de Goes Ribeiro ${ }^{1}$

Talvez estejamos muito condicionados a uma ideia de ser humano e a um tipo de existência.

Se a gente desestabilizar esse padrão, talvez a nossa mente sofra uma espécie de ruptura, como se caíssemos em um abismo. Quem disse que a gente não pode cair? Quem disse que a gente já não caiu?

Ailton Krenak

Resumo: O objetivo deste texto é enfocar a hibridização cultural a partir da indigenização do rap, ressaltando a educação como espaço-tempo de produção subjetiva na relação com a alteridade. Nesse sentido, o ensaio debate o conceito de "cultura" como um termo alienígena, ressignificado nas lutas dos povos originários. Para compor a metodologia, dialoga com o trabalho de rappers indígenas, não apenas como análise, mas visando à composição, isto é, integrando sons e imagens ao pensamento ensaístico do autor. O resultado é uma percepção sobre culturas e línguas, sem receios de ameaça ou de perda, visualizando possibilidades de reexistência e de uso estratégico, no caso, da poética e da estética Hip Hop. A pedagogia em jogo salienta demandas indígenas, como a demarcação da terra e a retomada da língua e da cultura, além de performatizar diferenças étnicas. Ademais, interpela a branquitude, seja para se articular às lutas, seja para compreender minimamente o recado: os povos indígenas não são objetos do imaginário de ninguém, mas sujeitos em desconstrução relacional com o mundo e que lutam pelo que acreditam, inclusive contra uma violência que já persiste por centenas de anos. O trabalho é um convite para a revisão de ideias preconcebidas por muitas paisagens sobre "o outro", como: enrijecimento identitário, generalização homogeneizadora e tentativa de construção de uma narrativa única. Mais que isso, quer provocar o purismo e a mesmidade, abrindo a produção de sentidos para o mistério da vida, isto é, o incognoscível.

Palavras-chave: Educação. Cultura. Rap indígena.

Abstract: The aim of this text is to focus on cultural hybridization based on the indigenization of rap, emphasizing education as a space-time of subjective production in relation to otherness. In this sense, this essay debates the concept of "culture" as an alien term, reframed in the struggles of the original peoples. To compose the methodology, it is necessary to discuss these questions based on indigenous rappers' works, not only as an analysis, but with a view to composition, that is, integrating sounds and images into the author's essayistic thinking. The "result" is a perception of cultures and languages, without fear of threat or loss, visualizing

\footnotetext{
${ }^{1}$ Professor da Universidade Federal Fluminense (UFF), unidade de Angra dos Reis. Doutor e Mestre em Educação pela Universidade Federal do Rio de Janeiro (UFRJ). https://orcid.org/0000-0003-3940-7492. williamgribeiro@gmail.com.
} 
possibilities of re-existence and strategic use, in this case, of Hip Hop aesthetics and poetry. The pedagogy at stake highlights indigenous demands, such as the demarcation of the land and the resumption of language and culture, in addition to performing ethnic differences. Furthermore, it calls for the whiteness, either to articulate the struggles or to understand the message minimally: indigenous peoples are not objects of anyone's imagination, but subjects in relational (de)construction with the world and who fight for what they believe, including against a violence that has persisted for hundreds of years. This paper is an invitation to review ideas preconceived by many landscapes about "the other", such as: identity stiffening, homogenizing generalization and an attempt to build a unique narrative. More than that, it wants to provoke purism and sameness, opening the production of meanings to the mystery of life, that is, the unknowable.

Keywords: Education. Culture. Indigenous Rap.

\section{Caos Indígena ${ }^{2}$}

Este texto tem como objetivo enfocar a hibridização cultural a partir da indigenização do rap, ressaltando a educação como espaço-tempo de produção subjetiva na relação com a alteridade. Assim, enfatiza processos interculturais que articulam comunidades indígenas e movimentos culturais, procurando compreender a política cultural mobilizada a partir do rap por distintos povos do país. A ideia é estudar a produção como efeito de relações fluidas, nos interstícios da cultura, compreendida de maneira heterogênea e relacional, jamais dada e transparente como unidade identitária. $\mathrm{O}$ presente ensaio destaca composições indígenas que fazem uso do rap na negociação de sentidos, deslocada das estratégias negro-juvenis (RIBEIRO, 2008). Com o dispositivo de luta política e de criação estética, povos indígenas performatizam diferenças, promovendo uma reexistência que transforma política e pedagogicamente suas vidas.

O trabalho está relacionado com estudos que venho produzindo desde 2007 com a cultura Hip Hop. No mestrado, debato a relação interculturalidade e escolarização com uma abordagem entre "o multiculturalismo crítico" e "o pós-colonialismo" (RIBEIRO, 2008). O doutorado deu menos ênfase ao referido movimento cultural, trabalhando aspectos escolares ligados a violências. O tema retorna no pós-doutorado, a partir do qual "a diferença" e "o currículo" passam a ser o mote em diálogos com "o pós-estruturalismo" (RIBEIRO, 2016). Já "a questão indígena" emerge na prática profissional com: experiências de colegas que atuam na área; demandas de estudantes; a prática curricular da instituição. Desde 2015, atuo na docência em um curso de pedagogia, assumindo as disciplinas de "Relações Étnico-raciais" e "Currículos". A partir de 2018, passei a atuar também no magistério indígena. Além de participar e coordenar eventos de extensão ligados à interculturalidade, estabelecendo relações com comunidades tradicionais.

Nesse contexto, surge a surpresa de estudantes (não indígenas) com rappers indígenas, o que julgo ser relevante para esta proposta, sem pretensões de resolução, mas levando adiante o afeto. Tenho buscado compreender como "a cultura" tem sido tratada em educação; observando como "a interculturalidade" tende a ser considerada objeto de projetos políticos e pedagógicos utópicos, projeção da imagem desejável. Assim, destaco a questão: deslocar do realismo para as práticas discursivas, "enquadrando" regimes de verdade. Ou seja, o que está em jogo é que no horizonte das projeções para "um futuro melhor", ainda dispomos de poucos

\footnotetext{
2 Todos os títulos das seções deste texto foram inspirados em letras de rap indígena.
} 
recursos para trabalhar a maneira etnocêntrica com a qual costumamos lidar com a alteridade. A ideia é criar oportunidades para pensar a questão.

A partir disso, proponho considerar "a cultura" uma categoria, produzida com aspas em meio às múltiplas possibilidades de existência (CUNHA, 2017). Nesse caso, trata-se de um saber-poder mobilizado por distintos "regimes de verdade" que se entrecruzam, isto é, como prática de significação, efeito de poder, discursivamente produzido. Procuro diálogo com os estudos culturais e/ou pós-coloniais: Homi Bhabha, Arjun Appadurai, Gayatri Spivak, Jacques Derrida. Ademais, busco o oendu (escuta em guarani) com referências indígenas: Ailton Krenak, Daniel Munduruku e Davi Kopenawe, além de estudiosos indigenistas. Também contribuem Ana Ivenicki em educação multicultural, assim como Alice Casimiro Lopes e Elizabeth Macedo no debate curricular.

Esta proposta: em um primeiro momento, discute a perspectiva de cultura; a seguir, se lança na "questão multicultural"; posteriormente, apresenta a ideia de indigenização do rap, trazida em diálogo com letras produzidas por indígenas brasileiros; na sequência, tecendo uma composição que atravessa o estudo acadêmico, enfatiza questões que remetem à revisibilidade de perspectivas preconceituosas e estereotipadas; por fim, elabora uma seção final à guisa de conclusão.

\section{Espelho, espelho meu}

Haja vista o exposto, retomo "a cultura" e deslocamentos feitos em educação, enfatizando a dinâmica contingente da política cultural e processos normativos que envolvem a defesa da diversidade, propondo um debruçar-se vigilante sobre os termos, ou seja, sobre o que temos mobilizado a partir disso. Em outras palavras, minha preocupação é lidar com a ideia de cultura de modo que contribua para o trabalho educacional. Tratamos de realidades que não estão dadas para serem tomadas como "objetivos", adendo curricular sobre "os outros". O argumento é: modos de produção da "cultura" são relacionais e ambivalentes, envolvem no processo as dimensões "pedagógica" e "performática" (BHABHA, 1998). São tramados na enunciação a partir de múltiplas realidades e contextos incomensuráveis. Ou seja, colocam em jogo "as paisagens" (APPADURAI, 2004) que temos produzido sobre a alteridade, desconstruindo identidades imaginadas, sustentadas fragilmente pelos "conhecimentos" que temos "do passado".

Com Bhabha (1998), o pedagógico envolve o poder de convencimento em relação ao que imaginamos como "tradições". No performático, "a tradução", ou melhor, as tentativas intersticiais de traduzir "o que sabemos", as quais produzem um sentido (mais precisamente um efeito de sentido) quando enunciamos "a cultura". Este estudo se distancia, então, de um viés de solução, evolução, síntese, dialética, projeção utópica, ponto final, horizonte etc. A questão não é como a cultura deve ser. Ou seja, esperamos enquadrar "o enquadramento", nesse caso, "a cultura" com aspas, a qual é produzida por distintos "regimes de verdade" (CUNHA, 2017).

Para Raymond Willians (2007), culture é uma das palavras mais difíceis do vocabulário inglês. O autor possivelmente se refere ao caráter escorregadio para dar a "última palavra", uma vez que a perspectiva em mente do sociólogo é dicionarizar o termo, encontrando o/s significado/s aceitável/eis. Segundo Maria Elisa Cevasco (2003) e Denys Cuche (2002), a palavra "tem história" e no caso de "cultura" compreende muitos embates, inclusive entre os próprios europeus (França e Alemanha, por exemplo). Então, seu uso guarda relação com contextos, mobilizando e gerando efeitos que podem colidir de forma violenta com realidades e subjetividades, dando corpo a perspectivas de cunho universalista ou particularista. 
Em termos historiográficos, somos (in)conformados por ideias civilizatórias europeias que marcam o Brasil, preconizado pela ideia de "civilizados" versus "bárbaros"/“selvagens"/ "primitivos", até pouco tempo silenciando indígenas do ensino no país, conforme argumenta Giovani da Silva (2013). O aludido texto enfatiza a maneira como o ensino escolar de História tem lidado com os indígenas, apontando como desafio lidar com a diversidade social, cultural e linguística dos povos tradicionais. A denúncia é: a forma é preconceituosa e prejudica direitos históricos. São compreendidos como "genéricos", expressão cunhada por Darcy Ribeiro nos anos 1970, geralmente adorando "o Deus Tupã", vivendo em "tribos" e falando uma "língua única". Tratados "no passado", inclusive a partir de expressão pretérita, desaparecendo em grande parte da historiografia, restritos quase sempre ao "descobrimento". Com isso, lutas atuais e a diferença ficam obstaculizadas. A lei federal 11645/2008 altera a 10639/2003 a qual institui nas escolas públicas e privadas a inclusão da história e cultura dos povos originários. Sobre a referida legislação, o texto aponta um grande desafio: esperanças e desconfianças se misturam no processo. No caso, uma tentativa de transformação que pode contribuir para compreendermos "a nós mesmos". Para o autor, é "conhecendo o outro" que nos "conhecemos melhor”. O argumento é que a história não vem para substituir, mas oferecer instrumentos aos indígenas, os quais têm suas formas de narrar a vida, como os mitos. Cumpre lembrar que não se trata de ilusão, mas de uma maneira de educar. Ressalta ainda que a questão das teorias de aculturação elabora um discurso do fim dos povos indígenas, não correspondendo à realidade. Primeiro porque, diferente do previsto, estão aumentando "as etnias", reivindicando a diferença. Ademais, a busca por um "índio" legítimo é ilusória e estereotipada, marcada pela ideia essencialista.

A lei 11645/2008 representa, então, um conjunto de esforços para mudar a realidade. No plano filosófico, a ideia de progresso e de desenvolvimento humano com base em um padrão único tem produzido rastros evolucionistas, articulados por teorias racialistas do século XIX, com uma pitada de idealismo alemão hegeliano que vagueia em contextos e distintas áreas de saber, fortalecidos pela confusa leitura eurocêntrica do "povo brasileiro", atravessada por processos colonizadores que permanecem na prática imaginária de uma política educacional desigual e opressora.

A produção cinematográfica Brava Gente Brasileira, por exemplo, aponta a relação tensa e problemática dos Kadiwéu com os brancos no século XVIII. A ênfase está na crueldade, ignorância, arrogância branca, mas também nas estratégias de luta e de coesão do povo indígena, articulações políticas, embates culturais e na força guerreira. Estupros, assassinatos, usurpações, traições e distintas formas violentas de assimilação e de exploração são práticas realçadas na obra, capitaneadas pelos "civilizados" e simpatizantes "dos bons costumes". Indica rastros do dito "cidadão de bem", o qual, lado a lado com o aval religioso cristão, buscava justificativas para os mais hediondos atos. Na perspectiva opressora, tamanha violência se justifica pela necessidade de "correção". Não era "pecado", pelo contrário, até mesmo "ações virtuosas", já que "índios", considerados "selvagens", podiam ser tratados de qualquer forma. Nessa relação desigual, para os povos, não há saídas a não ser fazer uso de todas as armas, como no desfecho da armadilha dos Kadiwéu em que "oferecem" corpos femininos aos brancos para que pudessem perder a vantagem na batalha orquestrada. $\mathrm{O}$ desfecho não é nem de vitória e nem derrota, mas uma retomada da tradição, simbolizada pelo ato de cortar as orelhas do inimigo morto, uma resposta para as condições de produção cultural que aponta para uma batalha vencida, mas a guerra permanece.

É claro que "a cultura" pode ser pensada de várias formas, palavra essa importada para "terras tupiniquins". Mas, cabe lembrar que está inscrita em um léxico estrangeiro, isto é, não é uma categoria nativa. É razão suficiente para atentarmos para o uso das práticas normativas 
do termo. Não raras vezes, movimentos interculturais, processos, estratégias híbridas e heterogêneas são ignorados em nome da pureza. A despeito de maior volume de denúncias, gerado pelas redes midiáticas, persistem distanciamentos sociais em relação às realidades violentas com as quais indígenas lidam, bem como à multiplicidade de conhecimentos que produzem. É desafiador, então, ir de encontro à banalização da cultura, haja vista a pouca condição pedagógica e afetiva para nos distanciar de preconceitos que perpassam a sociedade. Admitir isso não é sinal de que devemos "lavar as mãos" ou desistir, mas de buscar caminhos para a reafirmação do político, reconhecendo a ignorância, o que demanda sempre muito estudo e trabalho de nossa parte.

Clarice Cohn (2016) destaca a tendência à folclorização ou à incorporação da "cultura" indígena ao currículo, mais ou menos específica, a depender do caso. A questão apontada pela antropóloga é que não há homogeneidade, nem nas demandas pelas escolas indígenas e nem na maneira como têm sido elaboradas as práticas pedagógicas. Nessa perspectiva, no entanto, se destaca o risco de práticas homogeneizantes fazerem parte das contradições escolares, pari passu com a suposta atribuição de mais autonomia e inclusão de sujeitos. Do integralismo à escola diferenciada, a política cultural segue com "pontos de vista": do Estado a partir da Constituição de 1988 e dos indígenas que passam a interagir, de distintos modos, cabe elucidar, com a demanda escolar em prática.

A autora nos diz que tendemos a lidar com a cultura como algo a ser assimilado à instituição, o que gera um processo desigual e problemático: a cultura está no cotidiano, incorporada pelos indígenas/não indígenas em suas vidas, seus corpos e relações; já "a cultura" costuma estar definida por "regimes de verdade" que opõem "saberes tradicionais" a "conhecimentos universais". Referenciais curriculares de formação indígenas, por exemplo, partem da política cultural, trabalhando com a dualidade "universal" versus "diferenciada". Um problema que o texto citado enfatiza é que não se costuma considerar o valor da escola para os indígenas. Algumas leituras excluem a escola da vida indígena; ou quando não recaem no oposto, dando exclusividade à escola e esquecendo-se do "modo de ser indígena", o qual interage com a instituição. Propõe, portanto, que observemos tais aspectos, destacando o valor que a escola tem localmente para distintas comunidades. Os exemplos desenhados com ênfase na etnografia ilustram de maneira pertinente, a meu ver, argumentos e afetos em jogo no que a pesquisadora ressalta.

O primeiro exemplo destaca a perspectiva Xikrin, que não tem adesão à escola diferenciada, preferindo que as crianças aprendam na escola "nos termos dos brancos". A questão em jogo para eles é a alteridade. O conhecimento escolar fica para as crianças, não é utilizado na aldeia, não é demonstrado quando adulto, tampouco tem utilidade. Nesse caso, "o desencontro se faz ainda mais visível. Enquanto professores não indígenas buscam trazer a cultura Xikrin para a escola, para 'valorizar', as crianças valorizam as aulas em que copiam textos da lousa e aprendem canções infantis vertidas para sua língua" (COHN, 2016, p. 322323). Ou seja, as crianças de tal comunidade étnica buscam conhecimentos não indígenas na escola. Nesse caso, cabe destacar que - ao que parece a indicação do texto - quando se busca incorporar "a cultura do outro" se promove desrespeitos à organização daquela cultura, incorporando-as a padrões: na escola estudada se oferece aulas de pintura corporal, mas sem respeitar o gênero e a idade adequados e nem a estética característica dos Xikrin, desprovido do sentido para aquela comunidade.

A informação é clara: na perspectiva de tal comunidade indígena, não querem ir para a escola aprender "os seus" conhecimentos, mas "os conhecimentos dos brancos". E demandam a escola como necessária, conforme Cohn (2016). Levando a pensar na especificidade dos indígenas com a escola e no valor atribuído à instituição, outro exemplo trazido é o dos Baniwa. 
Em comparação com o anterior, porém, o dilema é outro. Por se tratar de um povo reconhecidamente evangélico, demanda da escola que na "parte diferenciada" seja ensinada "a religião". Outra posição pode ser encontrada no mesmo povo: difere na parcela indígena convertida ao catolicismo.

A questão a essa altura é: o que fazer para tornar a escola respeitosa, conforme aponta a lei? A resposta não é simples, evidente ou está dado de antemão. Pelo contrário, demanda árduo trabalho, estudo e condições para lidar com a política cultural, se afastando do assimilacionismo, mas também da banalização das culturas na linha de uma diversidade normativa irreflexiva e pseudoaberta ao Outro. O desafio é que "a escola tende a ser, sempre, escola, e escolariza os modos de produção e transmissão cultural" (COHN, 2016, p. 334). Não sei se concordo com a generalização da antropóloga, mas acrescento que a relevância da perspectiva de "cultura" faz diferença. O que concordo é em fugir do maniqueísmo no qual a instituição é comumente vista. Não se trata nem da autonomização indígena (a autonomia pode ser doada por outrem?), nem da condenação da instituição como violenta para os povos originários. Estou de acordo que entender o que indígenas valorizam em cada contexto é o que potencializa a crítica e minimiza efeitos julgados pelos próprios como negativos, investindo também atenção à perspectiva de "cultura" na dinâmica da produção normativa.

Manuela da Cunha (2017) contribui ao abordar a questão da cultura com e sem aspas e os domínios distintos, embora indissociáveis, de "regimes de verdade", ou seja, formas através das quais produzimos conhecimentos considerados válidos. A antropóloga aponta haver lógicas distintas e ao mesmo tempo imbricadas. Cultura implica em uma organização endógena e dinâmica, vivida de distintos modos; já com aspas tem um caráter de abrangência e de etnicidade que, muitas das vezes, se confronta com o que se vive. $\mathrm{O}$ argumento dela é que diferentes regimes de conhecimento atuam e são diversos os contextos. Para que se possa compreender a questão, faz uso didático do recurso de escalas. Ou seja, o mesmo "indivíduo" pode ser considerado um membro de uma família Guarani Mbya; um Guarani Mbya na escala da "cultura étnica", mas também "um índio" para o parlamento nacional e um elemento de um povo para a Organização das Nações Unidas (ONU).

A reflexão sobre escalas traz implicações e, em alguns casos, equívocos. Conforme o texto, como um povo lida e compreende a cultura pode estar no registro de palavras de empréstimo, justamente para marcar a diferença que diz respeito à etnização do uso da "cultura". Cabe lembrar que não apenas é inventada, mas trata-se de um termo exportado, para o qual a antropologia contribuiu. Em outras palavras, uma coisa é o uso que fazemos das culturas ao nomeá-las e classificá-las (cultura com aspas); outra é a forma como cada povo faz uso do termo importado. Conforme a autora, o termo que vai, volta, isto é, passa a servir a propósitos da luta política. A cultura sem aspas não se dicotomiza à natureza para os indígenas; é vivida em um conjunto heterogêneo de relações que incluem o modo como cada povo lida com a "cultura". Passamos a outro domínio ao compor uma etnicidade, produzida com o não indígena, o que pode fazer crer na homogeneidade da cultura. Nessa configuração imaginária, há muitas armadilhas. Segundo o texto, uma delas afirma que o conhecimento científico tende a espelhar o tradicional. Como o primeiro tende a ser visto internacionalmente como "universal" e "homogêneo", se cai na armadilha de se opor a tal conhecimento uma homogeneidade também para os tradicionais. Mais um deslize compreende que conhecimentos tradicionais não se atualizam, permanecendo estáticos como se tratassem de "saberes do passado", imunes às transformações históricas e à mobilização conjunta de novas gerações e relações exógenas. "Tradicional" pode ser então lido dessa forma como imutável, talvez daí venha a estranheza com "indígenas rappers", mencionado anteriormente como mobilizador deste texto. 
Uma das questões que podemos destacar com preocupação é que qualquer interferência externa é vista genericamente como "perda". Nesse caso, Cunha (2017) enfatiza que entre "a coerência" e "a completude", o uso vernáculo opta sempre pela segunda, o que implica assumir as contradições como parte da vida. Ou seja, a questão não é "o resgate da tradição perdida", mas buscar compreender em que condições vêm se dando a produção cultural e na desconstrução dos "conhecimentos" que enrijecem a gnosiologia indígena em regimes de verdade que tendem à generalização e imobilismo. Por isso, tenho (des)focado enquadramentos normativos na política: o que é e não é do campo educacional, curricular, formação de professores etc. Com isso em mente, penso que o estudo do rap indígena pode oferecer pontos relevantes ao trabalho educacional.

\section{Meu sangue é vermelho}

Vimos que "cultura" se apresenta com muitas faces, com os seus rastros, ventilando distintos efeitos mobilizados por regimes de verdade e múltiplos mundos em desconstrução. Em uma perspectiva pós-estruturalista, trata-se de um significante que mobiliza um debate político em torno da significação (RIBEIRO, 2016). Não obstante, no que tange aos aspectos normativos em educação, especificamente, nos interessa as finalidades educativas, as quais "culturas tradicionais" podem se consideradas "adendo curricular", como se fosse um "fio de memória" incluída na "versão universalista", quer dizer, na máquina de produção de mesmidade, compondo "a unidade na diversidade". A ideia nesta seção é menos pensar em uma categoria analítica, conceitual, teórica; mais explicitar a queda ou o que confronta o padrão, apontado na epígrafe por Krenak.

Preocupada com questões pedagógicas que acometem a cultura escolar e a formação, Ivenicki discute as abordagens multiculturais (IVENICKI, 2018, 2019), isto é, distintas formas de responder à condição plural das sociedades contemporâneas: "folclóricas" ou "liberais" preconizam adendos ao currículo, deixando de explorar o caráter do poder, o que se limita a datas específicas, como "dia do índio" ou "semana da consciência negra", gerando um caráter exotista da cultura, tendo a norma como parâmetro; uma "perspectiva crítica/ revolucionária" busca a emancipação, aliadas às lutas sociais e debates em torno de políticas identitárias; "decoloniais" têm inspirações em autores latino-americanos na luta contra o colonialismo, ou seja, rastros mentais, sociais e culturais da colonização; nessa estrutura didática proposta pela pesquisadora, o "pós-colonial" se inspira em autores que estão pensando as culturas a partir da diaspórica, dando ênfase ao hibridismo e a maneira com a qual somos produzidos em contextos de deslocamentos e interculturalidade. Em tal perspectiva, a posição desliza entre abordagens críticas e pós-estruturalistas, buscando uma forma de hibridização teórica.

Política e pedagogicamente, a organização proposta pela pesquisadora faz sentido na medida em que trabalhada de forma didática, desejosa por responder à complexidade das sociedades. No plano teórico, trata-se de uma tarefa árdua hibridizar referenciais, para alguns talvez seja impossível. Nesse caso, pode-se objetar: como combinar o realismo que ampara o multiculturalismo crítico com a desconstrução de trabalhos pós-estruturalistas? A cultura coloca-nos diante de um grande desafio.

Nesse sentido, nem a demonização da escola e nem a banalização da cultura, julgo relevante pensar com o "pós-colonialismo", abordagem que a autora citada destaca, salientando que a opção da pesquisadora é dialogar com docentes, apresentando tendências. $\mathrm{O}$ argumento que busco neste texto no plano teórico compreende o aspecto relacional e incomensurável da cultura, não enfocando um projeto, quer dizer, para entrar na arena com "um lance" em nome da "autenticidade". Não quer dizer que apoie uma proposta neoliberal, apenas não tenho partido 


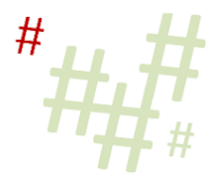

de fundamentos, mas de processos que são tomadas de decisão contingenciais. Por isso, enfatizo que este artigo é um exercício intelectual (sem grandes pretensões de aplicação) que busca compreender a política cultural, assumindo a prática de significação e os efeitos de poder no próprio trabalho.

Para isso, me parecem altíssonos os argumentos de Spivak (2010) sobre "a fala de sujeitos nos estudos subalternos"; a abordagem antropológica de Appadurai (2004) também contribui ao enfatizar o deslocamento da "cultura-substantivo" para "o cultural", fluxos da cultura em processos de produção imagéticos compostos por paisagens; por fim, oferecendo alternativa teórica ao realismo, Bhabha (1998) aprofunda a hibridização na ambivalência, não como simples mistura, mas considerando o imponderável das negociações de sentido.

Spivak (2010) levanta a polêmica possibilidade do "subalterno não falar", o que demanda cuidados. Cumpre destacar que a obra está em diálogo com um contexto acadêmico específico, denominado "estudos subalternos". Não se pretende dizer que subalternos "não têm voz"; diferentemente, o que a autora põe em questão é que as vozes são sempre mediadas na academia, questionando uma posição privilegiada de poder com relação à organização internacional do trabalho que teóricos não assumem. Inspirada em Marx e Derrida, questiona o silêncio acadêmico, analisando estudos específicos de Foucault e Deleuze. As escolhas dos textos dos referidos filósofos não foram ao acaso, mas pela compreensão de que ambos buscavam questionar a representatividade, mas acabavam, segundo os argumentos da autora, deslocando o problema e reafirmando o que tanto criticavam. A questão então passa pela ideia de "tradução" (do estudado para o pesquisador) que objetifica o sujeito, possibilitando que também se fale "pelo outro" ou "no lugar dele". Isto é, engessamento de processos de subjetivação que obstaculizam a agência e a luta política pela transparência que se veste o pesquisador "emancipador dos outros". Assim, questiona discursos hegemônicos na academia, incluindo crenças na produção do saber com relação à ideia de representação (pesquisadores que falam "pelos outros"). Ou seja, sua crítica é a objetificação do Outro.

Para compor o argumento, a autora retoma dois sentidos de representação: "como ato político que fala pelo outro" e como "representação estético-filosófica". É claro que "o subalterno" falar literalmente não é a questão; mas se trata da produção intelectual que se intitula "estudos subalternos". Foucault e Deleuze se tornam exemplos na obra, por ainda manter o silêncio, qual seja: uma representação de si como transparente, reeditando o que critica: a fala (do Outro) ainda é intermediada pela academia. Dessa forma, desinveste o subalterno do agenciamento, ignorando a ideologia e o envolvimento da alteridade.

A crítica é direcionada, mas podemos aproveitar. Em que medida a ideia de cultura, de conhecimento da cultura ("do outro") não desinveste o agenciamento e objetifica o sujeito, mesmo quando esperamos ser críticos? A apropriação intelectual pode buscar revelar e conhecer "o outro"? Esse Outro pode ser representado por nós acadêmicos? Ela argumentaria que não. Já é efeito de nossos discursos pedagógicos, não uma tradução literal, por mais envolvidos que estejamos e experientes que sejamos diante das demandas com as quais dialogamos, conforme Alice Lopes (2018) não podemos nos livrar da retoricidade. Ainda que o pluralismo venha a traçar diferentes unidades, se opondo ao conservadorismo, não costuma traçar uma aposta no descentramento do sujeito, tampouco chamar a atenção para "o lugar" desigual do intelectual e do investigador em relação aos "sujeitos das pesquisas".

Uma questão e tanto para quem é pesquisador e lida com políticas públicas. Algumas das quais investidas de demandas discutidas em "comunidades tradicionais". Debate difícil, afinal, não temos que decidir, escolher e tomar partidos? Como contribuir com políticas culturais contra as desigualdades sem em algum momento não supor a identidade, acabar 
generalizando e falando pelo Outro? Como fazer política de outro modo? Em termos distintos, como fazer política sem partir do que imaginamos que o Outro seja?

A crítica vem pela perspectiva do sujeito individual ou "o agente individual". Segundo esclarece Spivak na obra citada, o sujeito não pode ser o indivíduo; é descentrado. O agenciamento que possibilita agir "no lugar do outro" é resquício do sujeito moderno, regime de verdade reinstaurado, mesmo na ideia de que "cada um fala por si só". Nesse caso, esconde o essencialismo e o capital socializado. O pesquisador define o sujeito, a despeito da diferença e heterogeneidade. Para a autora, o sujeito acaba se unindo ao imperialismo no discurso. Nesse sentido, continuamos falando pelo/sobre "o subalterno". Para enfrentar isso, propõe uma teoria da ideologia, não desenvolvida na obra, sugerindo o questionamento da violência epistêmica, por faltar uma consciência da reinscrição topográfica, ou seja, "a escrita do lugar", a qual seria do intelectual/pesquisador; não raras vezes, como a autora aponta: homem, cristão e europeu.

Com isso, proponho enfrentar com vigilância a crítica colocada por Spivak: nem ignorar "o lugar do pesquisador", nem a topologia da subjetivação. Nesse caso, uma saída pode ser a que indica a autora, com J. Derrida: apelando ao "quase Outro" ou "o Outro em nós", assumindo uma alteridade radical, jamais satisfeita. Quer dizer, podemos desconfiar de/ interrogar processos colonizadores em nós, negar a assimilação, não há possibilidades de se assimilar o Outro, a menos como ilusão imagética; há sempre uma relação: eu-Outro; mesmidadealteridade. Há sempre a singularidade da enunciação. $O$ desafio é que a representação não definhou e o "pós-representativo" ainda continua representando "a seu modo" "o subalterno", "as minorias", "o diferente". Spivak (2010) apela para intelectuais mulheres, marxistas e feministas, criticando o realismo, o qual mata a agência e o agenciamento, por isso "o subalterno" continua sendo falado por intelectuais. Em suma, nenhuma interpretação vai dar conta da alteridade, toda a tentativa de fixar é uma operação de poder. Quer dizer, lidar com o rap indígena, enfatizado nas seções seguintes, assume percepções de um corpo que pesquisa, escreve e interpreta a partir de suas experiências, não esperando dar nenhuma palavra final ou espécie de interpretação peremptória.

\section{Mãos vermelhas}

Figura 1 - fotograma do videoclipe "Caos Indígena” do rapper Wescritor (povo Tupinambá de Olivença)

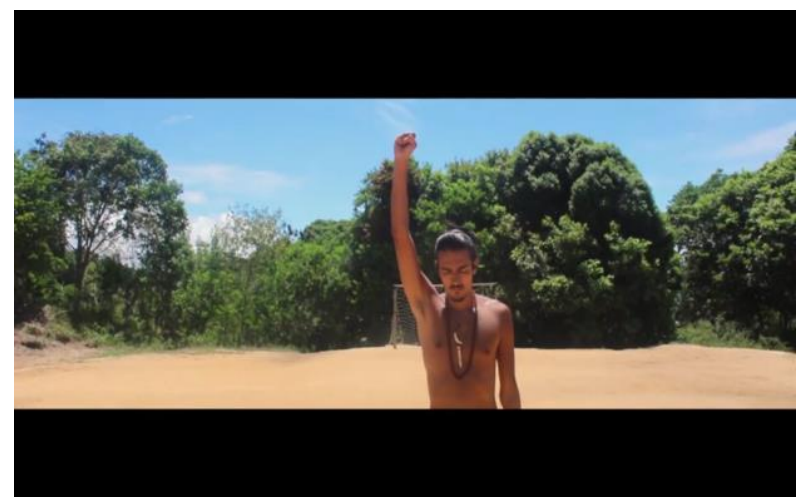

Fonte: elaborado pelo autor (2020)

Na Figura 1, vemos um rapper Tupinambá de Olivença, nascido em Santos, litoral de São Paulo. O fotograma, produzido com recursos de câmera de celular, "congela" uma imagem que faz um "corte" no corpo do artista, mostrando: o dorso praticamente nu, apenas com colares 
indígenas; a cabeça ligeiramente inclinada para baixo; um dos braços levantado para o céu; punhos cerrados. Em segundo plano, está a mata, recorrentemente mencionada em suas letras (WESCRITOR, 2019). No caso, a ilustração lembra reverência à ancestralidade indígena, resistência, reexistência e demandas, reconhecendo a mata como um valor intrínseco à vida, pelo qual vale a pena lutar.

O rap é amplamente difundido como uma das manifestações poéticas e estéticas da cultura Hip Hop, a qual se dissemina a partir dos "guetos norte-americanos" e se globaliza nos anos 1980/1990. Um dispositivo que mobiliza ações de cunho social, comumente reconhecido pelos adeptos como mobilizador e contra-hegemônico. Em função de articular sujeitos e vozes da exclusão, não há rap sem uma dimensão de realidade e desejo de transformar a sociedade. De uma forma geral, enfatiza: a luta antirracista e violências contra a população negra, contra mulheres, contra jovens pobres e crianças das camadas populares; a resistência e reexistência nas "favelas, periferias e quebradas"; relações injustas de trabalho, desigualdades e falta de oportunidades; críticas às instituições, as quais incluem a escola e a violência policial; questionamentos à política, aos políticos e à corrupção. O próprio rap e/ou a cultura Hip Hop podem fazer parte das letras, entre outros assuntos que visam à valorização da arte de rua, não apenas forma de expressão, mas transformação da realidade indesejável. Considerando tais aspectos: o que acontece se o rap for indígena?

A aparente proliferação do rap indígena não pode ser vista de maneira generalizada e descontextualizada, desconsiderando tensões internas, como conflitos intergeracionais, por exemplo. Também é o caso do Hip Hop. Portanto, não se trata de romantizar, nem um e nem o outro. Cabe lembrar que "cidade" é um significante em disputa, dentro e fora da aldeia, o que mobiliza um processo pedagógico contingencial e local, ou seja, captura e é capturado pelos indígenas. "O auditório", em alguns casos, são os próprios indígenas, geralmente em uma convocação para a mobilização na luta coletiva, afinal "Mbya Kueri [o indígena] não desiste" (OZ GUARANI, 2018). Em alguns casos, o interlocutor é "o branco", o qual desconhece e ignora as culturas e vidas, não compreende a história dos indígenas, gerando danos sociais, culturais e políticos: "O índio é forte e sobrevive jogado à própria sorte/ Como pode, sem terra pra morar, sem rio para pescar/ O Juruá [não indígena] desmata a mata e mata os M'bya [indígenas]" (OZ GUARANI, 2018).

"O orador" é quase sempre um/a indígena ou coletivo (como os Brô MCs) que transita/m entre a cidade e a aldeia, luta pelo seu povo, representando "a verdade" e "a comunidade". A verdade de quem canta é tema comum no rap, indicando antagonismo em relação ao que é dito por outrem, como mídia, políticos etc. Desse modo, uma das demandas é o próprio reconhecimento, performatizando a diferença cultural. A tecnologia e o uso da língua são destaques, ressaltando que as mudanças e apropriações não os fazem "menos índios", pelo contrário, indigenizam a cultura não indígena. Nesse caso, "a pele", como em Corpos Laranjas (WESCRITOR, 2019), indica força essencial, mas também “o modo de ser" que inclui a relação ancestral em que decisões são tomadas pelo invisível ou espiritual, muitas vezes inacessíveis até mesmo para a comunidade indígena.

Pensando nas questões normativas escolares, Danielle Lopes (2017) problematiza em que medida o aspecto formal da instituição e o estado negligenciam e/ou subalternizam a importância do invisível na política cultural. O texto não deixa de reconhecer mudanças que foram importantes e significativas para os povos originários, como as escolas indígenas, a Constituição Federal de 1988 e os documentos curriculares recentes que estabelecem a educação diferenciada e intercultural como um direito indígena. A questão é que a própria ideia de diversidade cultural caminha com uma normativa igualitária e universalista de 
conhecimento. Mais que isso, costuma subalternizar modos próprios de saber e embates que apontam aspectos inegociáveis e inacessíveis.

O aludido texto traz, a partir de estudos etnográficos, a importância do segredo, alguns que nem mesmos os indígenas têm acesso, como dito, já que se estabelece na relação do indivíduo com a divindade, "nem mesmo o presidente e nem a secretaria de educação podem ter acesso" (LOPES, 2017, p. 114). Para esses povos, decisões a respeito da assunção do próprio magistério como uma profissão (aliás, como em todas as outras profissões) são resultados da escolha divina. A fala dos Xeramoi (mais velho) remete à divindade, logo, não cabe nas "interrupções democráticas" dos brancos. Outro exemplo é o da "liberdade". "Não há horário para aprender na nossa cultura", ressalta Sandra Benites (uma Guarani citada no referido texto). Adultos contam histórias à noite para as crianças em volta da fogueira, não havendo a necessidade das crianças acordarem cedo para serem educadas. Em suma, a autora vem buscando entender a escolarização dos Guarani, destacando a hibridização e a negociação que os povos fazem do que vale a pena para a aldeia (e o que não vale) na relação com o estado e seus "documentos para serem seguidos".

Kalna Teao et al (2016) também enfocam produções curriculares entre os Guarani Mbya, tomando como perspectiva enunciações corporais e (des)encontros com a escola. Partem de distintas experiências que envolvem a docência e saberes indígenas na escola, incluindo Sandra Benites como uma das autoras (a mesma Guarani mencionada anteriormente). Identifica povos no Espírito Santo, destacando tensões, desafios e possibilidades. O referencial inclui "o decolonial", "o pós-colonial" e "pós-estruturalismo". Um dos destaques está no deslocamento dos indígenas, compreendido não como migração, mas como "mobilidade". Defendem que não existe um único fator para a mudança e construção do território Guarani. "A busca da terra sem males" e "a religiosidade" não explicam em sua completude a mobilidade, mas a histórica e social luta pela terra e as relações com a sociedade, o estado e as demais comunidades indígenas. Outras questões: doenças, álcool, violências e também a condição ambiental podem interferir na decisão da mobilidade que é uma marca identitária. O texto destaca ainda o elemento "escola indígena" na vida Guarani como uma aposta e uma conquista, mas que apresenta problemas a serem observados, os quais colocam em debate a própria ideia de interculturalidade.

As razões apresentadas são críticas no que tange à escolarização, já que tem limitado a autonomia indígena, não valoriza seu modo de ser e oprime. Alguns exemplos a esse respeito evidenciam a tensão, como no texto anteriormente citado em relação ao invisível. Já Teao et al. (2016) destacam o desrespeito com a menstruação e a alimentação das meninas, as quais demandam cuidados: não comer nada quente, não pegar brisa e descansar, por exemplo. Por sua vez, o "tempo de educar" não se dá por uma única pessoa e nem no turno da manhã. As crianças precisam estar com seus pais à noite. Trata-se de enunciações corporais que se (des)encontram com a escola e suas práticas normatizantes. Nem tudo pode ser traduzido para o escolar e a negociação ocorre com os indígenas, os quais buscam na escola uma forma de se fortalecer. Outro ponto está na ideia de projeção com a qual a interculturalidade vem sendo pensada. Nesse sentido, a perspectiva de "diferença" articulada à igualdade só pode ser pensada como diversidade. É um problema, a meu ver, para a educação escolar indígena, já que se limita ao que se imagina "saber a respeito".

Domingos Nobre (2016) destaca a infância Guarani e a preocupação com as mudanças culturais em virtude da energia elétrica e da escola, defendendo a interculturalidade crítica que tem como norte o futuro dos povos originários e a autonomia diante das decisões que os afetam. Levanta assim questões relativas ao capitalismo e os efeitos na cultura. Preocupação também dos mais velhos com quem dialoga, o que ainda gera a recusa de alguns desses em matricular crianças Guarani em escolas. Em geral, a educação formal apresenta dificuldades em 
compreender o processo educativo em ambientes não escolares. Segundo o texto, crianças podem passar a serem educadas pela disciplinarização dos corpos, adaptando-se "ao mundo" Juruá (dos brancos) por intermédio de uma "escola tradicional". Como "fronteiras vivas", a infância preocupa o autor, realçando sensibilização pedagógica e antropológica. Destaca ainda que a luz elétrica insere os indígenas em interesses e curiosidades que geram afastamento da cultura indígena, confrontando-se com tradições.

No entanto, destaca a guaranização das práticas, a qual implica numa relação própria dos indígenas com a escola, brinquedos e tecnologias, o que interessa a este texto elucidar. $\mathrm{O}$ trabalho com filmes mencionados pelo autor ressalta toda uma preocupação com a língua e com o respeito à palavra, sobretudo dos mais velhos. Isso me fez lembrar a experiência que tive com os Mbya no magistério quando exibimos um vídeo, despertando surpreendente atenção e espantoso interesse. Recordo-me ainda de uma criança muito pequena que frequentava as aulas e que estava no meio da sala com o celular. Ela jogava e se divertia, mas me sugeria que era com um modo distinto do que estava acostumado a ver crianças Juruá: sentada no chão e bem livremente enquanto acontecia a aula com os adultos.

Nesse debate, também contribui Mariana Paladino (2010). De caráter antropológico, explora um terreno pouco discutido: a educação escolar indígena em contextos urbanos, se contrapondo à ideia de "perda cultural" ou desagregação dos grupos de parentesco. Questiona antropólogos que buscam a autenticidade e esperam ser porta vozes dos indígenas, se inquietando com a escolarização. Assim, argumenta em defesa da perspectiva não essencialista que compreende o deslocamento dos indígenas para as cidades, no caso dos Tikuna, do Alto Solimões, como multifacetado e complexo. Não há uma única razão e nem pode ser compreendida de maneira estática na medida em que aumenta a demanda pela escola, seja na aldeia, seja na cidade, não se limitando a fatores econômicos. Segundo o texto, uma das mudanças se dá na relação entre a agricultura, a roça e a oferta de trabalho assalariado. Os mais velhos resistiam à escola, mas novas gerações começaram a demandar a instituição a partir dos anos 1990, percebendo na escola possibilidades de ascensão, dentro e fora da aldeia. O preconceito de estudantes e professores na época com os Tikuna era grande, considerados "burros", por não saber o português. Até o final dos anos 1980, eram punidos com palmatória na escola. Além da relação roça/cidade, a escola também pode significar um distanciamento de conflitos da organização interna da referida comunidade indígena, constituída por clãs.

A ideia de se "civilizar", fincada em relações ideológico-religiosas, também é um destaque do artigo. É um fator que mobiliza os Tikuna na busca pela cidade e pela escola. No caso, uma procura por status, mas também por afastamento de álcool, danças e práticas pagãs, ou seja, não cristãs e evangélicas. Há uma questão a respeito dos bens materiais e simbólicos do "mundo dos brancos", o que desperta curiosidade dos jovens de experimentar a diferença. Diferentes valores em jogo, para alguns o conteúdo tem menos importância, o capital cultural da escola é o que vale. Há casos em que o professor "branco" é preferível, para mais facilmente ensinar o português; há também quem defenda professores Tikuna no contexto de uma educação diferenciada e sensível a valores culturais da aldeia. Para a autora, o povo está em busca de distintos modos de escolarização, diferenciada ou não, na aldeia e na cidade, não pondo a questão em oposição. A demanda por escolas na aldeia é grande, inclusive de nível superior.

Outro exemplo da indigenização, a qual fortalece o argumento da contingência é trazido por Adriana Corrêa (2019) quando faz uma leitura da obra de Márcia Wayna Kambeba, indígena pertencente ao povo Omágua/Kambeba, localizado no alto Solimões, Amazonas. Trata-se de uma indígena geógrafa, poetisa, musicista e fotógrafa que vive na cidade (São Paulo). A perspectiva é cunhada sobre a ideia de "entrelugar", em diálogo com autores que se 
debruçam sobre interculturalidade, diáspora, migração, identidade e território. No entanto, pouca problematização é feita em relação a diferenças entre as referências teóricas. No caso, Nestor Canclini, Homi Bhabha, Stuart Hall, Darcy Ribeiro e outros são reconhecidos como amparo para as ideias da pesquisadora. A despeito disso, o referido texto chama a atenção para relação coerente entre os diversos recursos nos quais a indígena se expressa, trazendo tensões para os modos de vida. A leitura é que a mesma se constitui em harmonia com a natureza, mesmo não estando na aldeia. Os valores e tradições a acompanham, entrando em embates com "o mundo não indígena". "Mulher, terra e meio ambiente" são articulados e por isso não cabe na ideia de posse do "mundo branco" e capitalista. Ela pode ser então definida como "um rio entre duas margens". Em uma delas está "o mundo indígena" e na outra "o não indígena". A indígena não está nenhuma e nem outra, mas "entre", imersa no fluxo de sua singularidade.

A leitura que a autora faz parece "resolver o problema" com o uso do termo "entrelugar". Porém, podemos lembrar que a hibridização em Bhabha não aponta a fronteira entre "um lá" e "um cá", mas como a única coisa que existe. Ou seja, em tal abordagem, não há um rio entre duas margens que separam "identidades de cada lado". Mas, seguindo o próprio poema, só há $o$ rio, isto é, o rio é a fronteira fluida a partir da qual a singularidade segue produzindo a negociação de sentidos. Assim como o poema, ela é o rio e como tal não há possibilidade de sentido pleno. Como alteridade e mistério, o que pode ser feito é compreender a manifestação na qual se estabelece uma leitura e não a perspectiva que dará conta do que pensa e quer dizer a indígena.

No contato dos indígenas com o rap, a ideia da performatividade de si se dá por várias vias, em alguns casos através de rádios e internet, em outros há uma intervenção direta de grupos ligados ao Hip Hop, como a CUFA (Central Única das Favelas), cabendo lembrar que regiões onde se situam os indígenas apresentam problemas de moradia e saneamento básico, semelhantes aos das favelas, como as de São Paulo e do Rio de Janeiro. De acordo com um dos jovens do Brô MC's: "Aldeia é como uma favela. O que muda é que lá eles usam fuzil e aqui é facão... muita gente acha que o índio é como se fosse um lixo". (KEVIN apud NASCIMENTO, 2013, p. 262). Considerando tais aspectos, se compreende que é "sempre é mais que um som/cé refúgio de dores afinadas em tom para fugir dos naufrágios” (SOUTO MC, 2019).

Tomando como base o trabalho dos Brô MCs (NASCIMENTO, 2013), em diálogo, sobretudo com autores da linguística contemporânea e decoloniais, o referido estudo propõe que as categorias "língua" e "identidade" sejam repensadas, tomando "processos transidiomáticos" como sustentação. A proposta problematiza o que chama de "visão distópica acadêmica de base eurocêntrica e anglo-saxão", concernente à ideia de "dominação cultural" ou "aculturamento indígena", dialogando com a seção anterior. O argumento é que "a proposição vernácula" se relaciona com processos de cunho global, como no caso do rap, mas dando rumos que podem servir de base antagônica à sociedade branco-ocidental. Afinal, "eu nasço e renasço na cena, mas volto melhor/ Renasço das cinzas de povos que deram suor" (MC WERA, 2018). A língua não está dada, mas viva, o que contribui para pensar a performatividade dos jovens indígenas diante das lutas e mazelas sociais. O rap como um elemento da cultura de contestação Hip Hop apresenta características não só de identificação cultural, mas de possibilidades de transformação local, já que "nosso luto virou luta/ nossa arma é a arte" (MC WERA, 2018).

Seguindo o argumento, a "sampleficação", isto é, composições com fragmentos musicais; a "representatividade", busca pela "verdade do grupo"; e a "fluidez" da cultura (NASCIMENTO, 2013) compõem a linguagem que potencializa distintas apropriações. O uso de um recurso global como o rap não ameaça a cultura indígena, mas potencializa um novo dispositivo que põe em movimento vozes e demandas dos povos originários. A mistura de 
línguas ou o que chama de "transidiomático" põem em curso uma hibridização que não se dá pela ideia de perda, mas de valorização cultural, ao passo que vislumbra um alcance ampliado da voz coletiva que sofre com a violência, com a exploração de fazendeiros e com demais interesses que tomam os indígenas como um empecilho para gananciosos desejos de supremacia civilizatórios (PREZIA, MAESTRI e GALANTE, 2019). E eles lembram: "políticos matam usando a caneta/ essas linhas passadas eu já sei de cor” (MC WERA, 2018).

Estamos tratando do "presente-futuro" e da relação intercultural assimétrica, mas que se reinventa na reexistência dos povos. A ideia de que "não são índios" por usarem tênis ou "roupas de marca" está em uma matriz racista e em uma perspectiva estereotipada, reedita o essencialismo e o racismo com fins de dominação e superioridade colonial, como aponta a seguinte letra: "índio para mim tá bem longe/ andando pelado e não tem carro não" (KATU MIRIM, 2020). Enfrentamento comum para indígenas, pelo visto. Para Katu, a resposta é a seguinte: "tenho o que quiser e que se foda sua opinião/ Você está ligado então, eu não preciso de permissão" (KATU MIRIM, 2020). Já para Wescritor: "sou, sem adereço, foda-se o apreço/ Eu vou fazer por nós" (WESCRITOR, 2019).

As demandas indígenas são incorporadas ao rap, como a demarcação da terra e a retomada, sendo recorrente a chamada para a luta (às vezes articulada à população negra) e a crítica social ao "branco", lembrando várias vezes da história colonizadora pós-cabralina. Além de performatizarem suas identidades com o rap, reivindicam o direito à liberdade de fazerem o que quiser da sua cultura, além de lembrarem as violências, os assassinatos de ontem e de hoje, a devastação das florestas e o impacto na natureza provocado pelo modo de vida ocidental, o que interfere no modo próprio de ser que vive a cultura de maneira indissociável da natureza.

Assim, o rap indígena reafirma um teor político e estratégico, como em: "Nossa cara é se curar, se organizar/ Nunca mais nos catequizar. Retomada, morada do nosso lar. De uma vez por todas, demarquem já!" (SOUTO MC, 2019). O antagonista é visto como ardiloso e egoísta, insensível à perspectiva indígena. A ideia de uma retomada, ou seja, de um despertar para a questão da terra, da floresta, da aldeia, do modo de ser, da língua e da cultura é apontado no discurso, incluindo uma articulação entre povos e um sentido de pertencimento coletivo, cultural e natural ao mesmo tempo. A música se constitui como um recurso a mais para a luta e para a articulação política, mas também para dar um recado àqueles que não os compreendem ou que tentam controlar seu modo de ser, dizendo como devem se comportar ou se vestir, considerando que: "É dor demais, só que é tempo demais/ Então sem essa de esperar pra soltar a voz, LUTEM!” (WESCRITOR, 2019).

O artigo de Luciana de Oliveira (2016) defende a ideia de que a configuração da música rap indígena dos Brô MCs se dá em um contexto de fórum cosmopolítico, atualizando a "palavra-alma", central para a cultura e a cosmologia indígena; com "a palavra-reza" e "a palavra-rap". "Xondaros [guerreiros], guerreiros, herdeiros da aldeia, sou índio Guarani/ Eu rimo e vou mandando em Guarani, escuta aí" (OZ GUARANI, 2018). E reafirmo, escuta aí: "Kunimin Gué Kunha Taingué kyri guei py tu nhavô jerekoike [os jovens e as crianças toda noite entram na casa de reza]/ Poy ojerojy mborai omonhendu tataxinare ko haxy'i Pavê hapotei omombey [fazem suas dança e pedem força para todos os parentes]" (OZ GUARANI, 2018). O texto da pesquisadora indica que o rap não é modismo ou bem de consumo que domina a cultura, tornando-a sujeita à homogeneização. De outro modo, o argumento é que indígenas promovem um movimento de indigenização do rap, mantendo a importância da cultura e a reexistência diante da forma de uma vida dura que levam.

"Em mil e quinhentos chegou o tal do Cabral/ No Brasil 22 de Abril, já havia donos dessas terras" (MC WERA, 2018). A contextualização histórica traçada a respeito dos indígenas 
no país e dos jovens rappers aponta para uma abertura que não se fecha em conhecimentos universalistas e totalizantes. Para Oliveira (2016), o pop serve a fins particulares relidos no contexto dos indígenas, marcado pelas duras lutas, no caso no Mato Grosso do Sul, com latifundiários, fazendeiros e comparsas jagunços; luta contra o estado, o qual desmerece a experiência da população e direitos; luta contra o preconceito e discriminação não indígena. Estamos falando de vidas desgastadas diante das condições impostas: suicídios, mortes, genocídios que marcam a experiência dos jovens que esperam falar "para os seus" e também para "os brancos" que não os enxergam. É uma luta diária e desgastante, como sugere o rap da Katu: "Eu não cansei/ eu não cansei" (KATU MIRIM, 2020). O rap entra no contexto de uso estratégico da "cultura" no sentido de fortalecer externamente um vínculo de afirmação, solidariedade e pertencimento. Portanto, não se trata de uma simples mistura. Na própria explicação de um dos rappers: "a gente não mistura. A gente coloca junto" (Kelvin dos Brô MCs apud OLIVEIRA, 2016, p. 211).

Algo permanece junto, mas não se mistura com a percepção do que são. É claro que mudanças necessariamente já ocorrem na própria adesão ao rap, como a dança, roupas largas e cordões dourados que aparecem nos clipes. O corpo que canta, também dança, grafita etc. Nesse contexto, há caixas de som na aldeia; bicicletas e cavalos; roupas largas e símbolos da cultura global (na mesma política da imagem) com a reverência aos ancestrais; pés descalços e pés com tênis de marcas famosas; enfim, inúmeros aspectos da reexistência indígena no rap que não cabe juízo de valor. Para alguns, "liberdade de consumo": "vou desfilar com meu cocar e com a sua bolsa Prada" (KATU MIRIM, 2020); para outros, rejeição dos valores capitalistas: "Nike e SKR é tua parada/ lixo vazio, muito egocentrismo" (WESCRITOR, 2019). Quem decide isso?

Julia da Silva (2016) também aborda as "práticas transidiomáticas" em letras de rap dos Brô MCs, salientando o caráter de hibridização e a estratégia de luta na relação negociada e dialética entre global-local. Se opondo à lógica purista que atrela "língua, território e identidade cultural", a qual serve a fins ideológicos e ilusórios de sentido homogêneo de nação, a ideia é compreender como se dá a negociação dos grupos, não mais restritos ao território, mas na dinâmica "desterritorialização/territorialização" da vida social contemporânea. Portanto, diferente da linguística clássica e de áreas influenciadas pela lógica purista, grupos locais não perdem cultura, não há aculturação. A hibridização é fomentada pelas necessidades e formas de ver de cada abordagem. É um trabalho que argumenta em defesa da ideia de mistura de línguas e culturas, incorporada à performatização identitária dos jovens Kaiowá, estratégias de se fazer ouvir por um público mais amplo. Portanto, sobrevivência e resistência diante de uma situação de assassinatos promovidos pela sociedade não indígena e pelos conflitos nas aldeias. "Sim, lutamos, resistimos e contamos com a ajuda de todos pra que as vidas de nossos parentes sejam salvas..." (WESCRITOR, 2019).

Em diálogo com teóricos que compreendem a relação global-local não de forma dicotômica e fatalista, Silva (2016) apresenta aspectos que nos ajudam a perceber a refletividade e conscientização diante das línguas que reterritorializa "o português" e $o$ rap com fins particulares. Não é um movimento único, há casos de rappers, lembrados no referido texto, que põem juntos espanhol, português, inglês e guarani, o que convoca pensar a língua não como um elemento abstrato, mas como política e dinâmica. A reapropriação demonstra um movimento de fluxos linguísticos que mobilizam a defesa da cultura e da língua, fazendo-as alcançar cenários inimagináveis. Assim, em vez de perda, há uma expansão das possibilidades diante das letras de rap. Paulo de Tássio Silva (2019), estudando os processos de política de revitalização da língua do povo Pataxó, sugere a desconstrução da ideia de "língua morta", apontando para a performatividade étnica e linguística. 
Outro destaque no rap indígena é a articulação das mulheres, lembrando a força do espectro ancestral: "Leoas rugem e nunca fogem/ Vozes que surgem cada vez mais forte/ Vida ou morte e morrer não é opção/ E as que se foram, canto pra ressurreição!” (SOUTO MC, 2019). A presença de mulheres é menor em coletivos, mas notória em propostas solo (Katu, Souto MC, Kaê Guajajara, entre outras), tendo como articulador o enfoque étnico e indígena. Em alguns casos, cedem parte de sua configuração diferencial para o encontro equivalente em torno da luta indígena. Mas, marcadores relativos às mulheres é parte do repertório: "Quero vê ceis falar que eu sou sexo frágil" (SOUTO MC, 2019).

Muitos vídeos estão com tradução (sobretudo, guarani para o português). Os clipes quase sempre passam uma sensação de ilustração de contexto, trazendo, não raras vezes, crianças, indicando preocupação com o futuro. Assim como também animais, rios, montanhas e áreas verdes. Denunciam derrubadas, queimadas, hidrelétricas e antenas de celular invadindo terras indígenas. Vários artesanatos e aldeias também são visibilizados, como também áreas da cidade. Símbolos e mensagens em cartazes estão ligados à triste e alarmante situação em constante ameaça. Ademais, recorrem a livros e à narrativa, como no caso de uma professora não indígena e o seu preconceito (ver. OZ GUARANI, 2018). Em algumas cenas imagens de shows; em outras, o cachimbo e a floresta.

O processo relacional não é simples, homogêneo, nem estático como se supõe, tampouco indica perda; mas efeito de decisões complexas que se dão de muitas formas, não previsíveis e necessariamente ligadas a causas que dialogam com o próprio rap de maneira singular. $\mathrm{O}$ dispositivo incorpora o discurso de batalha pela vida, alterando e sendo alterado, não incorporando a paisagem cultural como totalidade. Em outras palavras, nem tudo se mistura e o que se mistura não está dado. O próprio rap pode se alterar e novos atores políticos podem aderir à proposta, pode ser rejeitado em alguns coletivos, incentivado em outros. Tomar o rap e os povos indígenas como estáticos é deixar de compreender a dinâmica cultural/ da vida que é sempre intercultural e relacional: "Honrando não mais compromisso, nem Hip Hop/honrando o suor do povo de meus avós/ Honrando a minha vida, libertando eu memo/ Depois que plantar forte vai gera semente/ sem veneno, mas com muita língua afiada". Nesse caso: "tromba o porrete e as flecha voa" (WESCRITOR, 2019). Ou seja: há o enfrentamento da alteridade e a vida demanda resposta. A resposta é a flecha, a palavra.

Bráulio Loureiro (2016) aponta mudanças no rap no Brasil desde os anos 1990, caracterizando os anos 2000 como "nova escola". O enfoque é de expansão com pluralidade, ainda que tenha ficado marcado pelos movimentos paulistas no final do século XX. Apesar disso, muitas são as apropriações que nunca é simplesmente assimilação, mas um movimento de articulação a partir de uma releitura local que passa por interpretações e negociação dos adeptos. As maneiras de ser, fazer e ouvir rap não são homogêneas e tampouco deixam de abrir possibilidades. A ambivalência entre um dispositivo de "cultura de rua" e ao mesmo tempo de teor comercial, atravessa a história Hip Hop. Nesse sentido, a preocupação com o teor crítico é manifestada pelos rappers, destacando que a flexibilidade dilui a potência mobilizadora. O que é reivindicado em seu nome, o que o popularizou como ritmo e poesia, não necessariamente pode manter uma matriz de golpe social, debate já apontado em Ribeiro (2008). Porém, não se trata de adequação à moda, tampouco consumismo e ostentação, mas agenciamento: "tomando o gole desse sangue/ nóis viveu de monte em mangue/ hoje só vai jangada pra vocês/ Não é bom ser garçom e escolher o gosto do freguês?/ Então toma/ Deixei vocês no espelho pra enxergar vocês" (WESCRITOR, 2019). 
Figura 2: fotograma do videoclipe "Não cansei” da rapper Katú Mirim (povo Bororos)

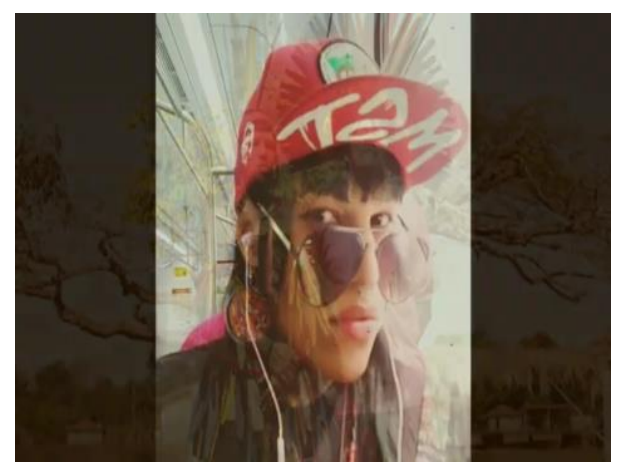

Fonte: elaborado pelo autor (2020)

Finalizamos esta seção, destacando a Figura 2, a partir da qual observamos uma imagem com a rapper Katu Mirim do povo Bororos, tradicionalmente, habitantes do Mato Grosso e que fala a língua Bororo. O fotograma mostra: o rosto e parte do dorso, vestindo uma blusa escura estampada. Há também acessórios, como: fones de ouvido e um boné vermelho que parece ser o do MST (Movimento dos Sem Terra), mas não completamente identificável e com um grafite à vista na aba - que está virada para cima, deixando à mostra parte do cabelo, um brinco de artesanato indígena e o olhar ligeiramente lateral, sobre os óculos escuros. Apesar da baixa visibilidade, em segundo plano, como no caso anterior, vemos uma área verde. Conforme procuramos trabalhar ao longo deste texto, a ilustração indica a interculturalidade na vida da artista; como vimos antes, Katu faz questão de dizer que não precisa de permissão (KATU MIRIM, 2020). Ela nos lembra "mundos" postos juntos, a sobrevivência e a negociação ambivalente e incomensurável da cultura.

\section{Xe rohenoi eju orendive ${ }^{3}$}

O que põe o rap indígena em movimento, articulando valores, perspectivas raciais e étnicas distintas, indica outros modos de lidar com o estudo em educação, deslocando a armadilha normativa e questionando a homogeneização e a insensibilidade. Aponta para a dinâmica da vida. Ou seja, instrumento a mais para a desconstrução de preconceitos e estereótipos que assolam o olhar e o sentir, os quais costumam empreender uma teia de captura a partir da maquinaria de fantasia de si e "do outro", criando processos espelhados de amortecimentos de rebeldias populares, como no caso de bases curriculares mínimas com pretexto de salvar a educação do país.

Pensar a hibridização ajuda ainda a pensar a luta indígena como atual e complexa, viva na dinâmica contingencial das relações interculturais e intergeracionais, contribuindo com a abordagem educacional. É a alteridade que sempre retorna e nos alerta a respeito do que não sabemos e não temos condições de saber. Sujeitos não são estáticos, indígenas não são do passado, tampouco agem conforme um grande bloco coeso. Não há nenhuma cultura pura ou estática. O olhar generalista é tão absurdo quanto o reducionismo que se impõe a si mesmo

\footnotetext{
3 Segundo Oliveira (2016), era a música mais tocada na Rádio Web Yandé, a primeira rádio indígena do Brasil (www.radioyande.com/), hoje com mais de 400000 visualizações no Youtube. O título foi traduzido pelos rappers por: "Nós te chamamos, venha com nós” (BRÔ MC'S, 2010).
} 
sobre "o outro imaginado". Talvez com isso alteremos ou balancemos a esquizofrenia que sugere romantismo + distanciamento da vida indígena, deixando de atenuar o genocídio sobre ela ocasionado. As tecnologias podem e devem ser usadas pelos povos originários se assim o desejarem e o fazem muitos. Cabe dizer que não parecem "brinquedos nas mãos de crianças", como no caso dos "brancos", suprindo doenças psíquicas, como micro-doses de conforto; indicam estratégias de luta e sobrevivência para os jovens indígenas. Não se sabe até que ponto, novos enfoques e desfoques são possíveis; mas não se deve perder de vista que não somos nós a decidir. "Morô?" (OZ GUARANI, 2018).

\section{Referências}

APPADURAI. Arjun. Dimensões culturais da globalização. Lisboa: Editorial Teorema, 2004.

BHABHA, Homi K. O local da cultura. Tradução de Myriam Ávila, Eliana Lourenço de Lima Reis e Gláucia Renate Gonçalves. Belo Horizonte: Ed. UFMG, 1998.

BRÔ MC'S. Eju Orendive, 2010. Publicado pelo canal Cufatvddos. Disponível em: https://www.youtube.com/watch?v=oLbhGYfDmQg. Acesso em: 28 out. de 2020.

CEVASCO, Maria Elisa. Dez lições sobre Estudos Culturais. São Paulo: Boitempo editorial, 2003, p. 8- 40.

COHN, Clarice. A cultura nas escolas indígenas. In: CUNHA, Manuela Carneiro da; CESARIO, Pedro de Niemeyer (org.). Políticas culturais e povos indígenas. São Paulo: Editora Unesp, 2016, p. 313- 338.

CORRÊA, Adriana de Oliveira Alves. Márcia Wayna Kambeba: um mergulho entre as margens do rio. Muitas Vozes, Ponta Grossa, v. 8, n.2, p. 289- 311, 2019.

CUCHE, Denys. A noção de cultura nas ciências sociais. 2 ed. São Paulo: EDUSC, 2002.

CUNHA, Manuela Carneiro da. "Cultura" e cultura: conhecimentos tradicionais e direitos intelectuais. In: CUNHA, Maria Carneiro da. (org.). Cultura com aspas e outros ensaios. São Paulo: Ubu Editora, 2017, p. 304-369.

IVENICKI, Ana. Multiculturalismo e formação de professores: dimensões, possibilidades e desafios na contemporaneidade. Ensaio: Avaliação, Política Pública e Educação. Rio de Janeiro, v.26, n.100, p. 1151-1167, jul./set. 2018.

IVENICKI, Ana. A escola e seus desafios na contemporaneidade. Ensaio: Avaliação, Política Pública e Educação. Rio de Janeiro, v.27, n.102, p. 1-8, jan./mar. 2019.

KATU MIRIM. Não cansei, 2020. Publicado pelo canal Katu Mirim. Disponível em: https://www.youtube.com/watch?v=u_NpkkkzGTM. Acesso em: 28 out. de 2020. 
LOPES, Alice Casimiro. Sobre a decisão política em terreno indecidível. In: LOPES, Alice Casimiro; SISCAR, Marcos (org.). Pensando a Política com Derrida: responsabilidade, tradução, porvir. São Paulo: Cortez, 2018, p. 83- 116.

LOPES, Danielle Bastos. A presença do invisível em escolas indígenas: escolarização, diferença e cosmologia entre os povos Mbyá (Guarani) do Rio de Janeiro. Cadernos CIMEAC, Rio de Janeiro, v. 7, n. 2, p. 103-119, 2017.

LOUREIRO, Braúlio Roberto de Castro. Arte, cultura e política na história do rap nacional. Revista do Instituto de Estudos Brasileiros, Campinas, n. 63, p. 235- 241, abr. 2016.

MC WERA. Retomada de Terra, 2018. Publicado pelo canal Wera MC. Disponível em: https://www.youtube.com/watch?v=lczH-Uykz94. Acesso em: 28 out. de 2020.

NASCIMENTO, André Marques. Ideologias e práticas linguísticas contra-hegemônicas na produção de rap indígena. Signótica, Goiânia, v. 25, n.2, p. 259-281, jul./ dez. 2013.

NOBRE, Domingos. Entre a escola e a casa de reza: infância, cultura e linguagem na formação de professores indígenas guarani. Niterói: Eduff, 2016.

OLIVEIRA, Luciana de. Bro MC's Rap Indígena: o pop e a constituição de fóruns cosmopolíticos na luta pela terra Guarani Kaiowa. Revista ECO PÓS, Rio de Janeiro, v. 19, n.3, p. 199- 220, 2016.

OZ GUARANI. O índio é forte, 2018. Publicado pelo canal OZ Guarani. Disponível em: https://www.youtube.com/watch?v=iXIpDa28HQU. Acesso em: 28 out. de 2020.

PALADINO, Mariana. Experimentando a diferença - Trajetórias de jovens indígenas Tikuna em escolas de Ensino Médio das cidades da região do Alto Solimões, Amazonas. Currículo sem Fronteiras, Campinas, v. 10, n. 1, p. 160- 181, já./ jun. 2010.

PREZIA, Benedito; MAESTRI, Beatriz Catarina; GALANTE, Luciana. Povos Indígenas: terra, culturas e lutas. 1 ed. São Paulo: Outras Expressões, 2019.

RIBEIRO, William de Goes. Nós estamos aqui: o Hip Hop e a construção de identidade em um espaço de produção de sentidos e leituras de mundo. 2008. 211f. Dissertação (Mestrado em Educação) - Universidade Federal do Rio de Janeiro, Rio de Janeiro, 2008.

RIBEIRO, William de Goes. Remobilizando a pesquisa com o pós-estruturalismo: quando a diferença faz toda a diferença. Currículo sem Fronteiras, v. 16, n. 3, p. 542- 548, set./ dez., 2016

SILVA, Giovani José da. Ensino de história indígena no Brasil: algumas reflexões a partir de Mato Grosso do Sul. In: PEREIRA, Amilcar Araujo; MONTEIRO, Ana Maria (org.). Ensino de História e Culturas Afro-brasileiras e indígenas. Rio de Janeiro: Pallas, 2013, p. 133154.

SILVA, Julia Izabelle da. Práticas transidiomáticas e ideologias linguísticas no rap guaranikaiowá - Brô Mc's: a mistura guarani-português como estratégia de negociação cultural e de 
luta política. Domínios de Lingu@gem, Uberlândia, v. 10, n. 4, p. 1425- 1448, out./ dez., 2016.

SILVA, Paulo de Tássio Borges da. Políticas linguísticas de revitalização entre os Pataxó do território Kaí-Pequi. Dissertação de mestrado profissional (Linguística e Línguas Indígenas). UFRJ, Museu Nacional, Rio de Janeiro, 2019.

SOUTO MC. Ressurreição, 2019. Publicado pelo canal Souto MC. Disponível em: https://www.youtube.com/watch?v=Flp1nFKwla8. Acesso em: 28 out. de 2020.

SPIVAK, Gayatri Chakravorty. Pode o subalterno falar? Belo Horizonte: Editora UFMG, 2010.

TEAO, Kalna Mareto; SILVA, Paulo de Tássio Borges da; BENITES, Sandra. Produções Curriculares entre os Guarani Mbya do Espírito Santo (ES): enunciações corporais e os (des)encontros com a escola. Odeere: revista do programa de pós-graduação em Relações Étnicas e Contemporaneidade - UESB. Bahia, n. 2, v.1, p. 168-197, jul.-dez. 2016.

WESCRITOR. Caos Indígena, 2019. Publicado pelo canal Wescritor. Disponível em: https://www.youtube.com/watch?v=gPGoKxvKWYs. Acesso em: 28 out. de 2020.

WESCRITOR. Corpos Laranjas, 2019. Publicado pelo canal Wescritor. Disponível em: https://www.youtube.com/watch?v=gPGoKxvKWYs. Acesso em: 28 out. de 2020.

WILLIANS, Raymond. Cultura. In: WILLIANS, Raymond. Palavras-chave: um vocabulário de cultura e sociedade. São Paulo: Boitempo, 2007, p. 117- 124.

Recebido em agosto de 2020.

Aprovado em novembro de 2020. 